\title{
ELECTROCHEMICAL STUDY OF THE INTERACTION OF Ni(II) ION WITH PROTON PUMP INHIBITORS
}

\author{
Milton C. Das, Rajib Biswas, Humaiara Akter, M. Anamul Haque and A. A. Shaikh* \\ Department of Chemistry, University of Dhaka, Dhaka-1000, Bangladesh
}

Key words: Proton pump inhibitors, Glassy carbon electrode, Cyclic voltammetry

Currently, for the treatment of gastric acid-related disorders, proton pump inhibitors (PPIs) are used extensively because they can produce a greater degree and longer duration of gastric acid suppression and, thus, better healing rates, than histamine $\mathrm{H}_{2}$ receptor antagonists (Blume et al. 2006). PPIs are the most potent inhibitors of gastric acid secretion, with a potential to increase intragastric $\mathrm{pH}$ by several units, as well as hydrogen ion concentration by several hundred to thousand-fold (McColl 2009). Their mechanism of action involves inhibition of the $\mathrm{H}^{+} / \mathrm{K}^{+}$ATPase enzyme which is presenting gastric mucosal parietal cells. This enzyme is responsible for hydrogen ion secretion in exchange of potassium ions in the gastric lumen (Sheen and Triadafilopoulos 2011). As a result, PPIs can modify the bioavailability and absorption of essential vitamins and minerals both in the stomach and duodenum, which may also affect more distal absorption. PPIs act by irreversibly blocking the hydrogen/potassium adenosine triphosphatase enzyme system of the gastric parietal cells (Zajac et al. 2013). The proton pump is the terminal stage in gastric acid secretion, being directly responsible for secreting $\mathrm{H}^{+}$ions into the gastric lumen, making it an ideal target for inhibiting acid secretion.

It is highly important to the chemistry of several transition elements such as iron, cobalt, copper and molybdenum, because of their functions in living systems. Most of the first row transition metals are important for enzymes (Dlouhy and Outten 2013). They have one or both of two important properties: (i) some readily change oxidation state, (ii) acting as critical redox couples. Recently, it was found that nickel complexes with ligands of the salen type can selectively modify DNA and RNA (Sigel and Sigel 1996). They are biologically important and can form complexes with different ligands. Simple chemical interaction of $\mathrm{Ni}(\mathrm{II})$ and other metal ions with PPIs has also been rarely carried out elsewhere (Golubov et al. 1991).

In this work, cyclic voltammetric method has been employed because of its potential ability in investigating the redox behavior of electroactive species. The cyclic voltammetric study of various metal ions in presence of ligands has been investigated and reported elsewhere (Shaikh et al. 2005, 2006). Here, we are reporting cyclic voltammetric studies of redox behavior of Ni(II) and its interaction with PPIs such as omeprazole (Ome), pantoprazole (Pan), esomeprazole (Eso) and rabeprazole (Rab) in acetate buffer solution at various $\mathrm{pH}$.

A three electrode electrochemical system consisting of glassy carbon electrode as working electrode, $\mathrm{Ag} / \mathrm{AgCl}$ (satd. $\mathrm{KCl}$ ) as reference electrode and platinum wire as counter electrode was

*Corresponding author: <aftabshaikh@du.ac.bd>. 
used. Cyclic voltammetric measurements were performed using computerized electrochemical system (Model CHI 620D, electrochemical workstation by CHI Inc., USA). pH of the solutions were measured by $\mathrm{pH}$ meter (Metller Toledo, Germany). Cyclic voltammetric study of $1.0 \mathrm{mM}$ $\mathrm{Ni}(\mathrm{II})$ in acetate buffer solution at different $\mathrm{pH}$ (3.5, 4.0 and 4.5) was investigated at GCE in the potential window of +1200 to $-1000 \mathrm{mV}$. Fig. 1 (a) shows a CV of $1.0 \mathrm{mM} \mathrm{Ni(II)}$ in acetate buffer solution with scan rate of $100 \mathrm{mVs}^{-1}$ at $\mathrm{pH}$ 4.0. In the forward scan one cathodic peak $\mathrm{i}_{\mathrm{pc}}$ was observed at about $-810.7 \mathrm{mV}$, while in reverse scan no anodic peak was found.
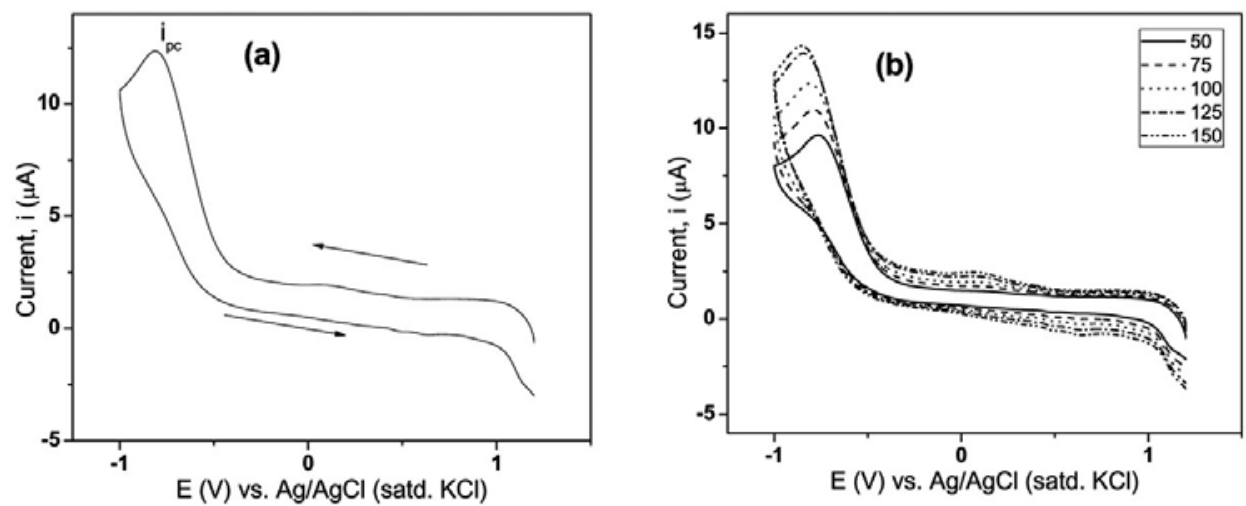

Fig. 1. (a) $\mathrm{CV}$ of $1.0 \mathrm{mM} \mathrm{Ni(II)}$ in acetate buffer at $\mathrm{pH} 4.0$ with scan rate $100 \mathrm{mVs}^{-1}$ and (b) $\mathrm{CVs}$ of $1.0 \mathrm{mM}$ $\mathrm{Ni}(\mathrm{II})$ at $\mathrm{pH} 4.0$ with scan rate: 50, 75, 100, 125 and $150 \mathrm{mVs}^{-1}$ at GCE.

The electrochemical response of $\mathrm{Ni}(\mathrm{II})$ under the identical condition (1.0 $\mathrm{mM} \mathrm{Ni(II)} \mathrm{at} \mathrm{pH} 4.0$ ) was examined by taking the CVs of $\mathrm{Ni}(\mathrm{II})$ with scan rate of $50,75,100,125,150 \mathrm{mVs}^{-1}$ as shown in Fig. 1(b). With the increasing of scan rate, the cathodic peak current increases which indicate the electrode process is diffusion controlled (Huo et al. 2009). Ni(II) shows only one cathodic peak which means an irreversible electrode process occurred in the redox process, which is also characterized by the shape. It is apparent that the peak current for the electrochemical redox reaction of $\mathrm{Ni}(\mathrm{II})$ in acetate buffer has a linear relation with square root of scan rates (Fig. 2(a)). This observation further suggests that the electrode process is diffusion controlled (Tan et al. 2007).

The effect of $\mathrm{pH}$ on the CVs for the redox reaction of $\mathrm{Ni}(\mathrm{II})$ in acetate buffer solution has been investigated at GCE. The CVs at different $\mathrm{pH}$ are shown in Fig. 2(b). It is observed that the peak height increases with the increase of $\mathrm{pH}$. It indicates that the electron transfer process is more pronounced at higher $\mathrm{pH}$.

The electrochemical study of the interaction of Ni(II) with Ome in acetate buffer solution at $\mathrm{pH} 3.5,4.0$ and 4.5 have been studied. The CVs recorded for $\mathrm{Ni}(\mathrm{II})$, and $\mathrm{Ni}(\mathrm{II})$ in presence of various molar concentrations of Ome (molar ratio of Ni(II)/Ome; $1: 1,1: 2,1: 3$ and $1: 4$ ) are shown in Fig. 3. The CV recorded for each ratio of $\mathrm{Ni}(\mathrm{II})$ and Ome, the peak current decreases and slightly shifted toward positive potential than those for only Ni(II). The results suggest that there 
is an interaction between $\mathrm{Ni}(\mathrm{II})$ and Ome. It seems that a relatively strong interaction occurs at 1:2 molar ratio of $\mathrm{Ni}(\mathrm{II})$ and Ome at all $\mathrm{pH}$ values.
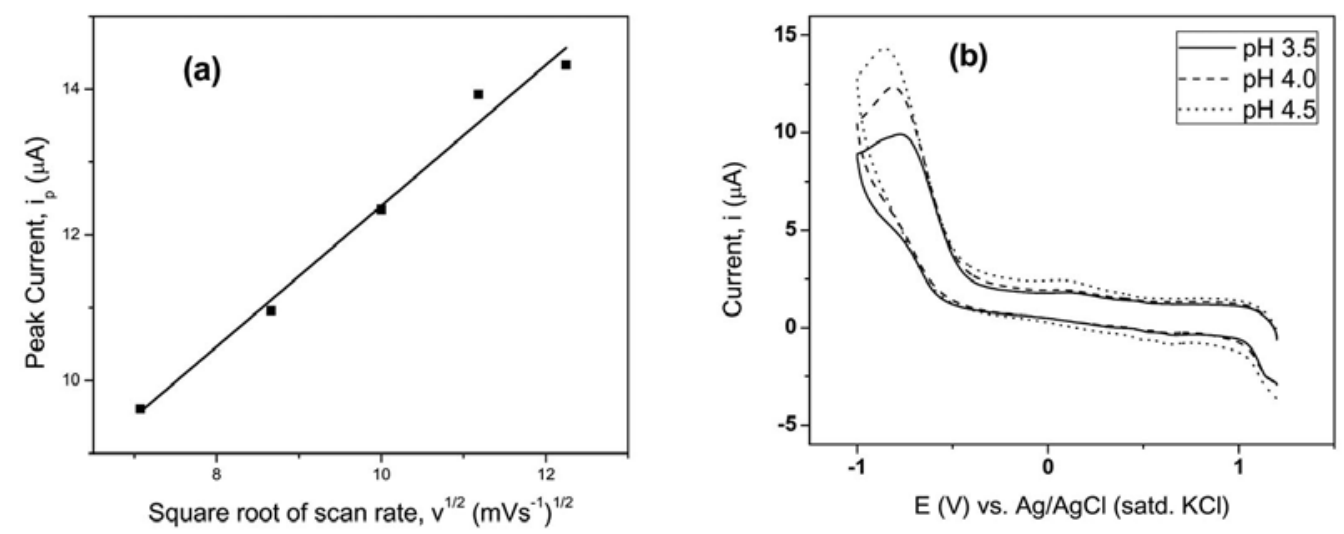

Fig. 2. (a) A plot of cathodic peak current as a function of square root of scan rate at $\mathrm{pH} 4.0$, (b) CVs of 1.0 $\mathrm{mM} \mathrm{Ni(II)} \mathrm{in} \mathrm{acetate} \mathrm{buffer} \mathrm{solution} \mathrm{at} \mathrm{pH} 3.5$ (solid), 4.0 (medium dot) and 4.5 (dotted).
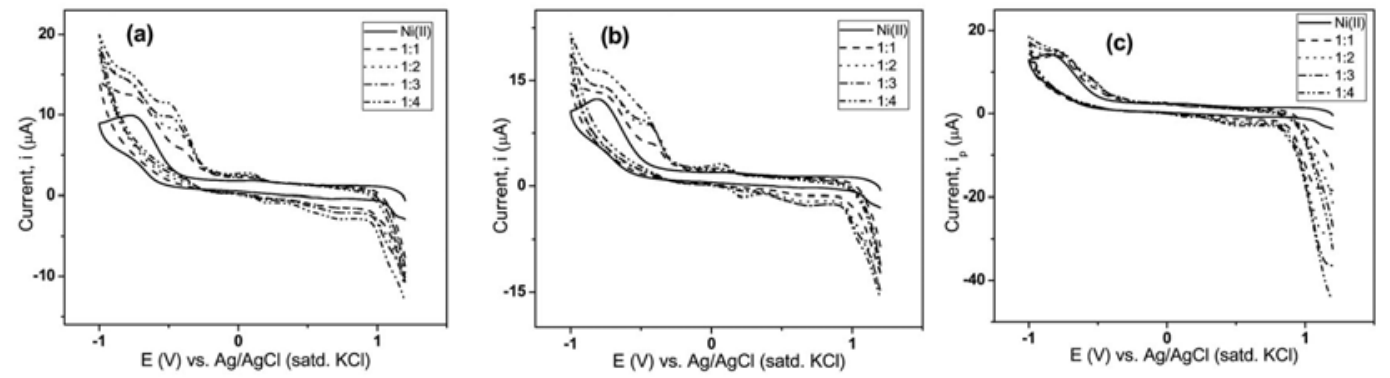

Fig. 3. CVs of $\mathrm{Ni}(\mathrm{II})$ (solid), and $\mathrm{Ni(II)/Ome} \mathrm{with} \mathrm{different} \mathrm{ratio} \mathrm{(i)} 1: 1$ (dot-dashed), (ii) $1: 2$ (dotted), (iii) $1: 3$ (long-dashed), and (iv) $1: 4$ (medium-dashed) in acetate buffer solution at (a) $\mathrm{pH} 3.5$, (b) $\mathrm{pH}$ 4.0 and (c) $\mathrm{pH} 4.5$.

The electrochemical study of the interaction of Ni(II) with Pan in acetate buffer solution at $\mathrm{pH}$ 3.5, 4.0 and 4.5 have also been carried out. The CVs recorded for Ni(II), and Ni(II) in presence of various molar concentrations of Pan are shown in Fig. 4.

The voltammogram recorded for each ratio of $\mathrm{Ni}(\mathrm{II}) / \mathrm{Pan}$, the peak current decreased and slightly shifted toward positive potential than those for free $\mathrm{Ni}(\mathrm{II})$ in all $\mathrm{pH}$ media. The results suggest that there is an interaction between $\mathrm{Ni}(\mathrm{II})$ and Pan and relatively greater interaction was found to occur at $1: 2$ molar ratio of $\mathrm{Ni}(\mathrm{II})$ and Pan.

The cyclic voltammetric study $\mathrm{Ni}(\mathrm{II})$ was carried out further in presence of Eso in acetate buffer solution at identical $\mathrm{pH}$ media. The CVs recorded for $\mathrm{Ni}(\mathrm{II})$, and $\mathrm{Ni}(\mathrm{II})$ in presence of various molar concentrations of Eso (Figure is not shown). The CV recorded for each ratio of $\mathrm{Ni}$ (II) and Eso, the peak current decreases and the peaks are slightly shifted toward positive 
potential than those for free $\mathrm{Ni}(\mathrm{II})$. The results also suggest that there is an interaction between $\mathrm{Ni}(\mathrm{II})$ and Eso at all $\mathrm{pH}$ and the interaction is relatively strong at $1: 2$ molar ratio.
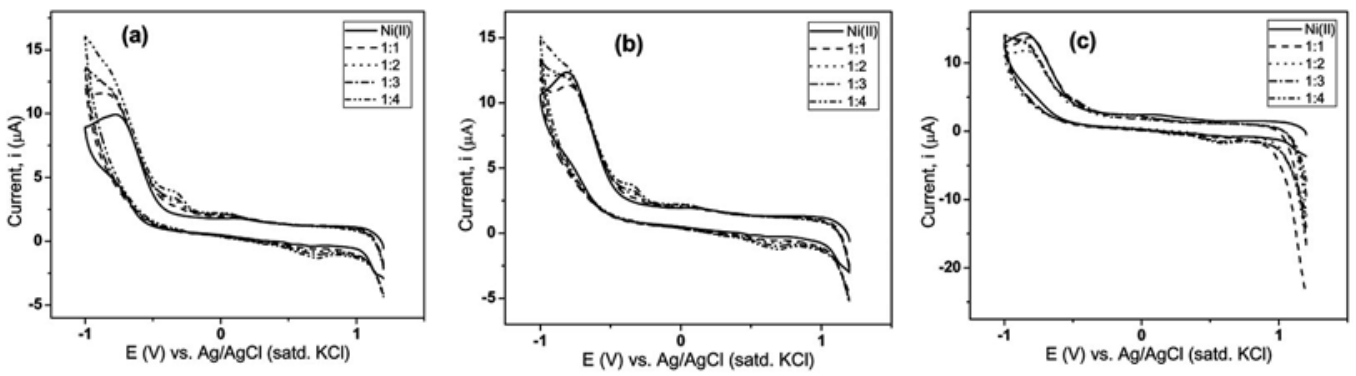

Fig. 4. CVs of $\mathrm{Ni}(\mathrm{II})$ (solid), and $\mathrm{Ni}(\mathrm{II}) /$ Pan with different ratio (i) $1: 1$ (dot-dashed), (ii) $1: 2$ (dotted), (iii) $1: 3$ (long-dashed), and (iv) $1: 4$ (medium-dashed) in acetate buffer solution at (a) $\mathrm{pH} 3.5$, (b) $\mathrm{pH}$ 4.0 and (c) $\mathrm{pH} 4.5$.
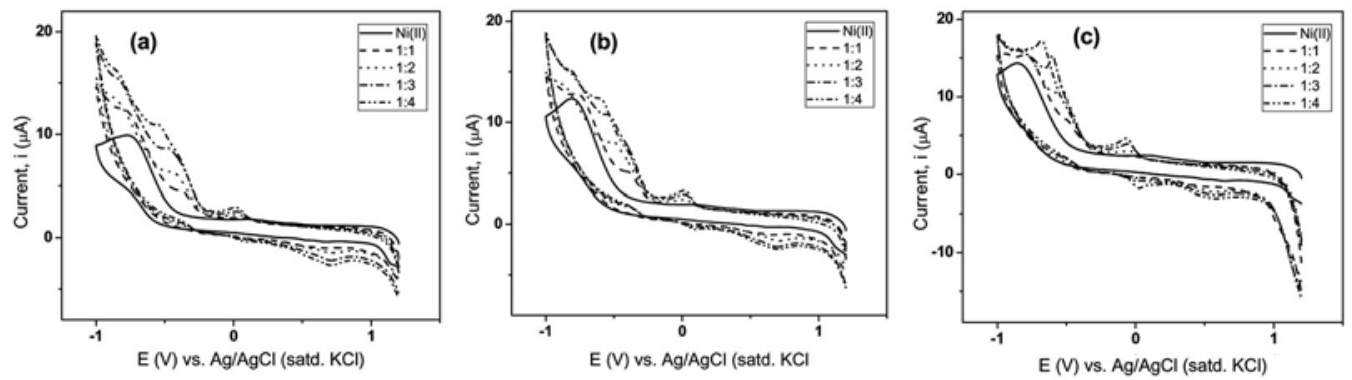

Fig. 5. CVs of Ni(II) (solid), and Ni(II)/Rab with different ratio (i) $1: 1$ (dot-dashed), (ii) $1: 2$ (dotted), (iii) $1: 3$ (long-dashed), and (iv) $1: 4$ (medium-dashed) in acetate buffer solution at (a) $\mathrm{pH} \mathrm{3.5,} \mathrm{(b)} \mathrm{pH}$ 4.0 and (c) $\mathrm{pH} 4.5$.

The electrochemical study of the interaction of Ni(II) with Rab in an identical condition has also been performed. The CVs recorded for $\mathrm{Ni}(\mathrm{II})$, and $\mathrm{Ni}(\mathrm{II})$ in presence of various molar concentrations of Rab are shown in Fig. 5. The CV recorded for each ratio of Ni(II) and Rab, the peak current also decreases and a slight shifting of the peaks was observed than those for free $\mathrm{Ni}(\mathrm{II})$. Additionally, a cathodic and an anodic peak (for Rab) are produced in presence of Rab in these media. The results suggest that there is also an interaction between $\mathrm{Ni}(\mathrm{II})$ and Rab.

In summary, the redox behavior of $\mathrm{Ni}$ (II) has been investigated in acetate buffer solution at various $\mathrm{pH}(\mathrm{pH} 3.5,4.0$ and 4.5) at GCE using the cyclic voltammetric technique. CVs of $\mathrm{Ni}(\mathrm{II})$ showed a cathodic peak in above mentioned $\mathrm{pH}$ and it showed irreversible behavior. Electrochemical studies on the interaction of $\mathrm{Ni}(\mathrm{II})$ with proton pump inhibitors (PPIs: omeprazole, pantoprazole, esomeprazole and rabeprazole) in acetate buffer solution were studied. In presence of omeprazole, the cathodic peak current for $\mathrm{Ni}$ (II) decreased than those of $\mathrm{Ni}$ (II) only. However, the peak almost disappeared in some cases. Moreover, cathodic peak was found to shift significantly towards the negative potential. Therefore, a strong interaction of Ni(II) and omeprazole occurred. The relatively strong interaction was observed at the molar ratio of $1: 2$ 
between $\mathrm{Ni}(\mathrm{II})$ and omeprazole. Almost identical behavior was noticed for the electrochemical interaction of $\mathrm{Ni}(\mathrm{II})$ and other PPIs (pantoprazole, esomeprazole and rabeprazole). These results encourage us for further study the insight into the interactions of metal ions with the PPIs.

\section{Acknowledgement}

The authors are grateful to the Ministry of Education, Govt. of the People's Republic of Bangladesh for the financial support.

\section{References}

Blume, H., F. Donath, A. Warnke and B.S. Schug. 2006. Pharmacokinetic drug interaction profiles of proton pump inhibitors. Drug Safety 29: 769-784.

Dlouhy, A.C. and C.E. Outten. 2013. Chapter 8. The iron metallome in eukaryotic organism. In: L. Banci Ed. Metallomics and the Cell. Metal Ions in Life Sciences 12. Spinger electronic book.

Golubov, J. and P. Flanagan and P. Adams. 1991. Inhibition of iron absorption by omeprazole in rat model. Dig. Dis. Sci. 36: 405.

Huo, H.Y., H.Q Luo and N.B. Li. 2009. Electrochemical sensor for heparin based on a poly (thionine) modified glassy carbon electrode. Microchim Acta 167: 195-199.

Lee, Y.C., E. Martin and F. Murad. 2000. Human recombinant soluble guanylyl cyclase: Expression, purification, and regulation. PNAS 97: 10763.

McColl, K.E. 2009. Effect of proton pump inhibitors on vitamins and iron. Am. J. Gastroenterol. 104: S5-S9.

Shaikh, A.A., S.N. Afzal, M. Q. Ehsan and A.H. Khan. 2005. Electrochemical study on redox reaction of iodine and bromine in presence of benzoylacetone at carbon electrodes. J. Saudi. Chem. Soc. 9: 279-286

Shaikh, A.A., M. Begum, A.H. Khan and M.Q. Ehsan. 2006. Cyclic voltammetric studies of the redox behavior of iron(III)-vitamin $\mathrm{B}_{6}$ complex at carbon paste electrode. Russ. J. Electrochem. 42: 620-625.

Sheen, E.and G. Triadafilopoulos. 2011. Adverse effects of long-term proton pump inhibitor therapy. Dig. Dis. Sci. 56: 931-950.

Sigel, A.; and H. Sigel, Eds., Metal Ions in Biological Systems, Vol. 32, 33, Dekker, New York, NY,USA, 1996.

Tan, L., Yao, S. and Q. Xie. 2007. Electrochemical determination of heparin using methylene blue probe and study on competition of $\mathrm{Ba}^{2+}$ with methylene blue for binding heparin. Talanta 71: 827-832.

Tedim, J., S. Patr'ıcio and R. Bessada 2006. Third-order nonlinear optical properties of DNA-salen-type nickel(II) and copper(II) complexes. Euro. J. Inorg. Chem. 17: 3425-3433.

Zajac, P., A. Holbrook, M.E. Super and M. Vogt. 2013. An overview: Current clinical guidelines for the evaluation, diagnosis, treatment, and management of dyspepsia. Osteopath. Family Physician 5: 79-85.

(Manuscript received on 20 May, 2015; revised on 9 August, 2015) 